\title{
Antioxidants and Other Micronutrients in Complementary Oncology
}

\author{
Uwe Gröber* \\ Academy of Micronutrient Medicine, Essen, Germany
}

\section{Key Words \\ Cancer - Micronutrient deficiency · Chemotherapy . Antioxidants · Selenium · Vitamin C}

\section{Summary}

Many patients being treated for cancer use micronutrient supplements, with the intention to complement their cancer treatment or help them cope with the therapy- and disease-associated side effects. The majority are adding antioxidants without the knowledge of the treating physician. There are many concerns that antioxidants might decrease the effectiveness of chemotherapy, but increasing evidence suggests a benefit when antioxidants are added to conventional cytotoxic therapies. However, it is imperative that physicians explore the use of antioxidant and other micronutrient supplements with their cancer patients and educate them about potentially negative as well as potentially beneficial effects.

\section{Introduction}

In Western European countries, the use of complementary medicine in cancer patients has increased steadily over the past 15 years. The majority uses this therapy to complement their cancer treatment or help them cope with the therapy-

*Mitglied der Arbeitsgemeinschaft Supportive Maßnahmen in der Onkologie, Rehabilitation und Sozialmedizin (ASORS) und des Arbeitskreises komplementäre Verfahren in der Onkologie (AKKOM) der deutschen Krebsgesellschaft

\section{KARGER}

Fax +497614520714

Information@Karger.de

www.karger.com (c) 2009 S. Karger GmbH, Freiburg

\section{Schlüsselwörter}

Krebs · Mikronährstoffmangel · Chemotherapie · Antioxidanzien · Selen · Vitamin C

\section{Zusammenfassung}

Viele Krebspatienten nehmen Vitamine und andere Mikronährstoffe ein, mit der Absicht ihre Therapie zu optimieren oder die therapie- und krankheitsbedingten Nebenwirkungen zu verringern. Die Mehrzahl der Betroffenen supplementiert antioxidativ wirksame Mikronährstoffe, häufig ohne das Wissen des behandelnden Arztes. Obwohl berechtigte Bedenken bestehen, dass Antioxidanzien die Effektivität der Chemotherapie beeinträchtigen können, geben aktuelle Studien erste Hinweise darauf, dass die Einnahme von Antioxidanzien sogar die konventionelle zytotoxische Therapie unterstützen kann. Es ist daher wesentlich, dass Ärzte ihre Krebspatienten vermehrt über die potentiellen negativen, aber auch günstigen Effekte von Antioxidanzien und anderen Mikronährstoffen aufklären.

and disease-associated side effects and improve quality of life. Along with herbal medicines (especially mistletoe), dietary supplements, particularly micronutrients and antioxidants such as vitamin $\mathrm{C}$ and selenium, are the most commonly used complementary therapies. This highlights the attractiveness for patients of biologically based therapies [1], but also suggests that patients who use such therapies without consulting health professionals may be at risk of side effects or interactions with conventional cytotoxic treatment [2-4]. Approximately $60 \%$ of all cancer patients take antioxidants during standard therapy without the knowledge of their oncologists

Uwe Gröber

Akademie \& Zentrum für Mikronährstoffmedizin

Zweigertstraße 55

45130 Essen, Germany

Tel. +49 2018742984

uweoroeber@gmx.net 
[5]. There are many concerns that antioxidants might reduce oxidizing free radicals created by radiotherapy and chemotherapy and thereby decrease the effectiveness of the therapy [6]. Therefore, it is imperative that physicians and oncologists explore the use of micronutrient supplements with their cancer patients and educate them about potentially negative but also potentially beneficial effects (especially in the palliative care setting).

\section{Malnutrition and Micronutrient Deficiencies}

Therapeutic success and healing processes in neoplastic diseases are strongly influenced by the nutritional status. For this reason, the patient's nutritional state should be determined as soon as the first diagnosis of cancer is made, and dietary care should be included in therapeutic planning from the very outset [7]. Malnutrition is one of the most common causes of death in cancer patients. By the time a tumor is diagnosed, about $50 \%$ of all patients have already lost weight. As many as $20 \%$ have lost over $10 \%$ of their initial body weight in 6 months, thus meeting the criteria for malnutrition. In a study on malnutrition in German hospitals, 38\% of the examined tumor patients were undernourished [8].

Numerous factors are involved in the development of malnutrition and micronutrient deficiencies [9]. In addition to the immediate consumptive effect of the tumor, the most important include anorexia (e.g. lack of appetite, premature satiation, food aversions, taste disorders), side effects of cancer therapy (e.g. nausea, vomiting), and hormone- and cytokinerelated metabolic disorders (fig. 1) [10]. Malnutrition compromises the immune system, organ function, and metabolism. The result is an increased frequency of complications from inflammation (for example of the mucous membranes), secondary infections (e.g. pneumonia and bedsores), life-threatening sepsis, extended hospitalization, and delayed wound healing. Cancer-related morbidity is approximately $30 \%$ higher in the presence of malnutrition [11]. The most severe form of malnutrition with wasting is called cachexia or cancer cachexia. It has an incidence of $60-80 \%$ in bronchial, stomach, and pancreatic cancer patients. After sepsis, cachexia is the second most common cause of death in cancer patients, and in $20 \%$ it is the primary cause of death $[12,13]$.

A typical diet comprises macronutrients such as carbohydrates, proteins, and fats, which constitute the majority of the individual diet, supplying above all energy, and essential micronutrients that are needed for immunological stability and numerous metabolic functions. Malnutrition is therefore a principal cause of inadequate micronutrient status of cancer patients. Thus, in addition to immunomodulating dietary therapy, the administration of micronutrients tailored to the respective indication and therapy is an important adjunctive measure of complementary and supportive therapies in oncology.

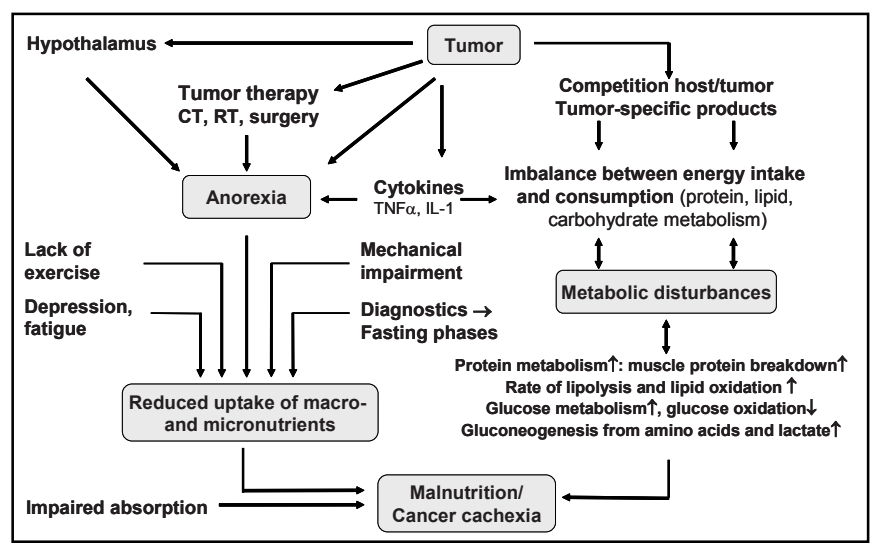

Fig. 1. Causes of micronutrient deficiencies in patients with cancer [10].

\section{Critical Micronutrients for Tumor Patients}

Micronutrient deficiencies may occur in cancer patients due to a variety of possible causes, including unbalanced dietary intake and adverse effects of treatment. In addition, many patients show signs of a chronic inflammatory response which can affect circulating concentrations of certain vitamins and trace elements [14]. Malnutrition existing even before the tumor manifests itself, poor appetite, and anorexia-related food aversion (e.g. from cytokines) are the major reasons that patients develop micronutrient deficiencies (fig. 1).

Compared to healthy individuals, tumor patients may already have measurably reduced concentrations of trace elements and vitamins (e.g. selenium, vitamin B12, vitamin D) in whole blood and serum by the time cancer is diagnosed and long before clinically relevant changes in nutritional status are seen [15-19]. At the same time, the supply and reserves of immunomodulating and antioxidative micronutrients (e.g. vitamin C, gamma-tocopherol) and nutrients that are not stored easily by the body can play a critical role (e.g. vitamin B1, folic acid) (table 1).

Cancer patients with chronic malnutrition and patients with bone marrow transplantation are at high risk of developing Wernicke's encephalopathy as a result of vitamin B1 deficiency [20]. Deficiency of vitamin D and vitamin B12 is prevalent among newly diagnosed cancer patients. In studies, up to $70 \%$ of cancer patients were found to be vitamin D insufficient, when vitamin $\mathrm{D}$ deficiency is defined as serum 25-hydroxyvitamin $\mathrm{D}<75 \mathrm{nmol} / \mathrm{l}$ [21]. Vitamin $\mathrm{C}$ deficiency is common in patients with advanced cancer. In a study of hospice patients, vitamin $\mathrm{C}$ deficiency was found in $30 \%$ of the cancer patients. Dietary intake of vitamin $\mathrm{C}$ was correlated to plasma vitamin $\mathrm{C}(\mathrm{p}<0.0001)$. Low dietary intake, low albumin, high platelet count, high C-reactive protein (CRP) level, and shorter survival were all significantly associated with low plasma vitamin C concentrations $(<11 \mu \mathrm{mol} / \mathrm{l})[22]$.

A changed mineral status can be observed in different tumor types and may influence the redox potential of patients suffer- 
Table 1. Critical micronutrients for tumor patients (selection)

\begin{tabular}{ll}
\hline $\begin{array}{l}\text { Micronutrient group (esp. antioxidants and immune } \\
\text { modulators) }\end{array}$ & Substance \\
\hline Vitamins & $\begin{array}{l}\text { vitamin D, vitamin B12, vitamin C, tocopherols, carotenoids, } \\
\text { vitamin A } \\
\text { selenium, zinc (e.g. head and neck cancer), iron, magnesium, } \\
\text { Minerals and trace elements }\end{array}$ \\
$\begin{array}{ll}\text { calcium } \\
\text { Litaminoids }\end{array}$ & $\begin{array}{l}\text { syndrome) } \\
\text { L-cysteine, L-glutathione (GSH) }\end{array}$ \\
Amino acids & $\begin{array}{l}\text { omega-3 fatty acids (EPA, DHA) (esp. in cancer cachexia) } \\
\text { vitamin B1 (SC 4-10 days); vitamin K (SC 2-6 weeks); } \\
\text { Essential fatty acids } \\
\text { Micronutrients with low tissue storage capacity (SC) }\end{array}$ \\
& $\begin{array}{l}\text { vitamin B complex (esp. folic acid, vitamin B6), vitamin C } \\
\text { and D (SC 2-4 months); vitamin E (SC 6-12 months) }\end{array}$
\end{tabular}

Table 2. Specific cytostatic-micronutrient interactions

\begin{tabular}{|c|c|c|c|}
\hline Cytostatic drug & Micronutrient [Ref.] & Mechanism & Possible consequences \\
\hline \multirow[t]{2}{*}{ Cisplatin } & magnesium $[52,25]$ & $\begin{array}{l}\text { renal } \mathrm{Mg} \text { excretion } \uparrow, \\
\text { intestinal } \mathrm{Mg} \text { absorption } \downarrow\end{array}$ & $\begin{array}{l}\text { hypomagnesemia, hypokalemia, metabolic } \\
\text { disturbances (e.g. lipid anomalies) }\end{array}$ \\
\hline & carnitine $[53]$ & renal carnitine excretion $\uparrow$ & hypocarnitinemia, risk of fatigue and lipid anomalies $\uparrow$ \\
\hline Pemetrexed & folic acid $[54,55]$ & folic acid antagonist & $\begin{array}{l}\text { diarrhea, mucositis, thrombocytopenia, neutropenia, } \\
\text { homocysteinemia }\end{array}$ \\
\hline Ifosfamide & carnitine [57] & renal carnitine excretion $\uparrow$ & $\begin{array}{l}\text { risk for carnitine deficiency after several CT cycles, } \\
\text { risk of fatigue and lipid anomalies } \uparrow\end{array}$ \\
\hline
\end{tabular}

$\mathrm{Mg}=$ Magnesium; CT = chemotherapy.

ing from solid cancers. Prospective trials with head and neck cancer patients have shown a decreased serum concentration of selenium ( $66 \%$ of all patients) and decreased activities of selenium-dependent glutathione peroxidase. In addition, a third of all patients had decreased zinc and iron levels, and $30 \%$ increased copper levels [23].

Requirements for minerals and trace elements in tumor patients cannot always be met even by a healthy diet with whole foods. Balanced nutrition is very difficult to achieve, especially during chemotherapy and/or radiotherapy because of the frequent side effects like nausea and vomiting. Anorexia and vomiting are often associated with electrolyte and acid-base imbalances. Chemotherapy- and radiation-induced damage of the mucous membranes (e.g. radiation colitis and diarrhea) adversely affects micronutrient absorption (e.g. folic acid, vitamin B12) and can cause major loss of micronutrients. Specific interactions between cytostatic drugs and micronutrients can also increase the requirement of micronutrients and should be taken into account when tumor-destructive therapies are planned. Cisplatin-based chemotherapies, for example, exert a significant negative effect on the magnesium und potassium metabolism, including an increased risk for hypomagnesemia and hypokalemia (table 2).
While basic oncological therapies (chemotherapy and/or radiotherapy) are very effective, they are also very aggressive. Because of their lack of selectivity, they damage not just tumor cells but normal tissues as well, especially the hematopoietic system (causing granulocytopenia, for example) as well as the rapidly proliferating cells of the mucous membranes (mucosal toxicity), the immune system (immunodeficiency, e.g. severe bacterial and viral infections), and the bone marrow. The mucous membranes in the bronchial and gastrointestinal systems are especially sensitive to chemotherapy or radiotherapy. Damaged intestinal mucosa leads to abdominal pain, destruction of the intestinal flora, increased loss of micronutrients (from vomiting and nausea), and impaired nutrient absorption (from diarrhea) and utilization (tables 3 and 4). As a result, the uptake of essential micronutrients is markedly reduced during chemotherapy and radiotherapy treatment.

In addition, one of the body's most important immune barriers in the gut (gut-associated lymphatic tissue, GALT) and the bronchial tract (bronchus-associated lymphatic tissue, BALT) is compromised so that pathogenic microorganisms can more easily penetrate the mucous membranes to gain entry into a body weakened by disease and therapy (bacterial translocation). This results in an elevated frequency of complications, 
Table 3. Side effects of chemotherapy, which are associated with an increased requirement of micronutrients and/or micronutrient deficiencies

\begin{tabular}{l} 
Side effect \\
\hline Nausea and vomiting \\
Diarrhea \\
Mucosal damage (mucositis) and ulceration of th \\
gastrointestinal tract \\
Anorexia (taste and smell disorders, loss of appet \\
premature satiation, food aversion) \\
\hline \\
\hline Lack of appetite \\
Nausea and vomiting \\
Taste and smell disorders, difficulty swallowing \\
Dry mouth \\
Diarrhea \\
Mucositis \\
Ulceration of the gastrointestinal tract \\
Fistulas (e.g. in the esophagus) \\
Acute and chronic radiation enteritis \\
\end{tabular}

Table 4. Side effects of radiotherapy, which are associated with an increased requirement of micronutrients and/or micronutrient deficiencies manifested in secondary infections and sepsis. The mucous membranes of the gut are the largest immunocompetent system of the body and perform essential local and systemic defense and monitoring functions in the healthy organism. In addition to chemotherapy and radiotherapy, surgical procedures on the gastrointestinal tract can also trigger malfunctions of absorption and utilization of micronutrients (table 5). It is also important to keep in mind the side effects of opioid analgesics and other adjuvant drugs (e.g. glucocorticoids, antidepressants, anticonvulsives, and neuroleptics) used for pain relief in tumor patients. Opioids have a strong constipating effect resulting both from a suppression of intestinal motility and intestinal secretions, and an effect on cerebral and spinal receptors. Aside from nausea, constipation is the most important and persistent side effect of the opioid analgesics. Pain therapy with opioids must almost always be accompanied by the use of laxatives. Once small intestinal passage is accelerated, complex nutrients are not adequately broken down. In addition, the absorption volume is reduced as well, because contact time with the absorbing epithelium is shortened. For these reasons, opioids and laxatives can lead to a major disruption of micronutrient digestion and utilization.

\section{Antioxidants and Chemotherapy - Still a Controversy}

Adjuvant oral administration of dietary antioxidants during conventional cancer treatment is still a matter of controversy, because the mechanisms of chemotherapy and radiotherapy are based in part on the production of free radicals [6]. However,

\section{Cytostatic drug}

highly emetic: cisplatin, dacarbazine, lomustine emetic: doxorubicin, epirubicin, daunorubicin, carboplatin, carmustine (BCNU), cyclophosphamide, etoposide, ifosfamide, mitomycin $\mathrm{C}$

fluorouracil, methotrexate, idarubicin, cisplatin, irinotecan doxorubicin, epirubicin, daunorubicin, etoposide, fluorouracil, methotrexate, vinca alkaloids (e.g. vincristine), mitomycin C practically all cytostatic drugs most of the cytostatic drugs currently used in antineoplastic therapy, for example antimetabolites, nitrogen mustard derivatives (e.g. cyclophosphamide), platinum coordination complexes (e.g. cisplatin), vinca alkaloids, paclitaxel, or anthracyclines, do not work primarily through oxidative stress [24, 25]. If antioxidants are truly a threat to the efficacy of standard therapy, antioxidant-rich foods, especially fruits and vegetables, ought also be prohibited during treatment [26]. In other words, this no longer justifies the often categorical rejection of supplementation with antioxidative and immunomodulating micronutrients during chemotherapy. Antioxidants such as vitamin C, vitamin $\mathrm{E}$, retinoids, or selenium act not just as scavengers but play a number of essential roles in metabolism in addition to their antioxidative, protective effect on the cells. Immune modulation, induction of apoptosis, and regulation of cell proliferation and differentiation are the most important of these.

Human, animal, and in vitro studies have shown that antioxidants can inhibit neoplastic cell growth by complex mechanisms. These include increases in neoplastic cell differentiation, increases in apoptosis, inhibition of protein kinase $\mathrm{C}$ activity, adenylate cyclase activity, and other mechanisms [50]. Isolated studies on cell cultures show that antioxidants such as vitamin $\mathrm{C}$, tocopherols, or carotinoids are able to selectively strengthen the growth-inhibiting effects of a variety of cytostatic drugs (e.g. fluorouracil, doxorubicin, and vincristine) on certain cancer cells $[27,28]$. On the other hand, the few available case studies and small-scale studies on tumor patients (discussed above) suggest that certain antioxidants, given under controlled circumstances, are able to increase the therapeutic efficacy of chemotherapy and radiotherapy by improving tolerance and heightening the sensitivity of the tumor while diminishing the toxic effects on healthy cell systems [26, 29, 30]. In a trial with 18 non-randomized patients (4 women and 14 men) with small cell lung carcinoma were given a combination of defined antioxidants (vitamins, trace elements, fatty acids, given orally) in addition to chemotherapy and/or radiotherapy [31]. Mean survival time was significantly longer, and the patients tolerated the chemo- and radiotherapy better with concomitant antioxidant therapy. Fourteen patients (77\%) survived for longer than 12 months, and 6 patients (33\%) longer than 2 years. 
Table 5. Operations in the gastrointestinal tract - sequelae which can trigger micronutrient deficiencies and/or an increased requirement of micronutrients

Table 6. Antioxidant combination: composition and daily dosage

\begin{tabular}{|c|c|}
\hline \multicolumn{2}{|c|}{ Organ / affected micronutrient group } \\
\hline \multicolumn{2}{|c|}{ Stomach (e.g. gastrectomy) } \\
\hline \multicolumn{2}{|c|}{ Vitamins } \\
\hline \multicolumn{2}{|l|}{ Minerals } \\
\hline \multicolumn{2}{|l|}{ Trace elements } \\
\hline \multirow{2}{*}{\multicolumn{2}{|c|}{$\begin{array}{l}\text { Small intestine (e.g. small bowel resection) } \\
\text { Vitamins }\end{array}$}} \\
\hline & \\
\hline \multicolumn{2}{|c|}{ Pancreas (e.g. pancreatectomy) } \\
\hline \multicolumn{2}{|c|}{ Vitamins } \\
\hline \multicolumn{2}{|c|}{ Vitaminoids } \\
\hline \multicolumn{2}{|c|}{ Essential fatty acids } \\
\hline Antioxidant & $\begin{array}{l}\text { Daily oral } \\
\text { dosage, mg }\end{array}$ \\
\hline Vitamin C & 6,100 \\
\hline D- $\alpha$-tocopherol & 1,050 \\
\hline Beta-carotene & 60 \\
\hline Copper sulfate & 6 \\
\hline Manganese sulfate & 9 \\
\hline Zinc sulfate & 45 \\
\hline Selenium & 0.9 \\
\hline
\end{tabular}

Table 7. Preliminary results of a randomized clinical trial using high-dose multiple antioxidants as an adjunct to chemotherapy (cisplatin and paclitaxel) in patients with non-small cell lung cancer [5]

\begin{tabular}{lcl}
\hline Treatment and tumor response & $\begin{array}{l}\text { Chemotherapy } \\
\operatorname{arm}(\mathrm{n}=29)\end{array}$ & $\begin{array}{l}\text { Chemotherapy } \\
\text { antioxidants arm } \\
(\mathrm{n}=28)\end{array}$ \\
\hline Chemotherapy cycles, median $\mathrm{n}$ & 3 & 6 \\
Patients completing 6 cycles, $\mathrm{n}$ & 11 & 16 \\
Complete response, $\mathrm{n}$ & 0 & 1 \\
Partial response, $\mathrm{n}$ & 9 & 15 \\
Stable disease, $\mathrm{n}$ & 5 & 4 \\
Progressive disease, $\mathrm{n}$ & 15 & 8 \\
Overall survival at 1 year, months & 7 & 14 \\
\hline
\end{tabular}

Non-small cell lung carcinoma (NSCLC) accounts for the great majority of all cases of lung cancer. In most NSCLC patients, by the time the tumor is diagnosed it is already inoperable because of extensive local growth or metastasis. Few of these patients survive longer than 5 years. In a randomized study, patients with advanced NSCLC were given a antioxidant combination (listed in table 6) $48 \mathrm{~h}$ before chemotherapy with cisplatin and paclitaxel [5]. The micronutrient combination was administered daily in oral form and continued over the entire treatment period and for 1 month after treatment was finished. Thereafter, micronutrient supplementation was
Deficiency of / elevated requirement for

vitamin B12 (from intrinsic factor deficiency), vitamins A, D, E, K, carotinoids (e.g. lycopene), folic acid (as a result of reduced $\mathrm{pH}$ gradients in the duodenum), vitamin $\mathrm{C}$

calcium (as a result of lactose intolerance, anacidity), magnesium zinc, iron (as a result of anacidity), selenium

vitamin B12 (resulting from microbial imbalance/dysbiosis); vitamins $\mathrm{A}, \mathrm{D}, \mathrm{E}, \mathrm{K}$, carotinoids (as a result of steatorrhea)

vitamins A, D, E, K, carotinoids (from steatorrhea), vitamin B12 coenzyme Q10

omega 3 fatty acids (from steatorrhea)

continued at half the dosage. Tumor response was better in the group that received the antioxidant combination in addition to chemotherapy than in the group that was treated with chemotherapy alone (table 7).

A recently published systematic review [29] of controlled, randomized studies on the influence of antioxidants on chemotherapy came to the conclusion that supplementation with antioxidants has no negative effect on chemotherapy, but rather has a favorable influence on the rate of adverse effects and on tumor response. None of the trials reported evidence of significant decreases in efficacy from antioxidant supplementation during chemotherapy. Many of the studies indicated that antioxidant supplementation resulted in either increased survival times, increased tumor responses, or both, as well as fewer toxicities than controls [29].

These data were confirmed by another publication of the same group of researchers [32] in 2008. The search of literature reached from 1966 to October 2007 using MEDLINE, Cochrane, CinAhl, AMED, AltHealthWatch, and EMBASE databases. Only randomized, controlled clinical trials reporting antioxidant-based mitigation of chemotherapy toxicity were included in the final tally. Searches were performed following a standardized protocol for systematic reviews. Only 33 of 965 articles considered, including 2,446 subjects, met the inclusion criteria. Of the supplements included in this review, antioxidant mechanisms range from free radical scavengers that act as reducers or that break lipid chains (e.g. glutathione, vitamin E, coenzyme Q10) to antioxidant enzymes formed by combining with a protein to form selenoproteins (selenium, glutathione). Other mechanisms include metal chelators (e.g. vitamin C) or cellular protectors from free radical attack (e.g. vitamins $\mathrm{C}, \mathrm{E}$ ) while some target and repair DNA aberrations (table 8, see online supplemental material). This review provides the first systematically reviewed evidence that antioxidant supplementation during chemotherapy holds potential for reducing dose-limiting toxicities. However, well-designed studies evaluating larger populations of patients given specific 


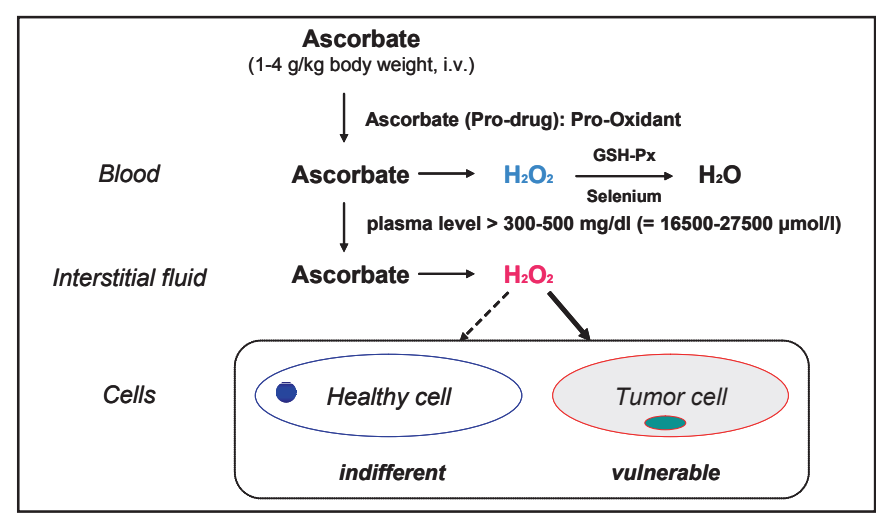

Fig. 2. Cytotoxic effects of ascorbate (modell) [48].

antioxidants defined by dose and schedule relative to chemotherapy are warranted [32].

As a matter of principle, in complementary oncology, supplementation of antioxidants and other micronutrients should always be tailored to the individual therapy protocol by taking into account substance-specific interactions between the cytostatic drugs and bioactive nutrients. Laboratory tests to determine micronutrient status (e.g. selenium in whole blood) and the appropriate monitoring are recommended.

\section{Selenium and Vitamin C - a Long Way to Evidence}

The two antioxidants most widely supplemented by cancer patients and used by complementary medicine practitioners are selenium and vitamin $\mathrm{C}$.

\section{Selenium}

Selenium is a component of selenoproteins some of which have important enzymatic and regulatory functions. These include the glutathione peroxidases which reduce hydrogen peroxide and harmful lipid and phospholipid hydroperoxides, the iodothyronine deiodinases that catalyses the conversion of thyroxine to the active thyroid hormone triiodothyronine, selenoprotein $\mathrm{P}$ which is involved in selenium transport, antioxidant and endothelial protection, and the thioredoxin reductases (TrxR) that are involved in DNA biosynthesis, regulation of redox-sensitive transcription factors, and regeneration of other antioxidants [10].

Epidemiological studies have shown an association between a low prediagnostic serum selenium concentration and the risk of cancer. In the Third National Health and Nutrition Examination Survey, serum selenium levels were measured in 13,887 US adults. The mean serum selenium level was $125.6 \mu \mathrm{g} / \mathrm{l}$. The multivariate adjusted hazard ratios comparing the highest $(\geq 130.39 \mu \mathrm{g} / \mathrm{l})$ with the lowest $(<117.31 \mu \mathrm{g} / \mathrm{l})$ serum selenium level tertile were 0.83 (95\% confidence interval (CI), 0.72-0.96) for all-cause mortality, and 0.69 (95\% CI, 0.53-0.90) for cancer mortality. However, the association between serum selenium levels and all-cause and cancer mortality was non-linear, with an inverse association at selenium levels up to $130 \mu \mathrm{g} / \mathrm{l}$ and a modest increase in mortality at high selenium levels above $150 \mu \mathrm{g} / \mathrm{l}$ [33].

Patients with breast cancer, gastric cancer, and colorectal cancer have significantly lower whole blood and serum selenium levels than healthy controls [34]. Selenium supplementation can reduce the side effects of conventional cytotoxic therapies (e.g. nephrotoxicity by cisplatin [35], mucositis by radiotherapy [36]) and enhance the antitumor activity of anticancer drugs through better compliance, fewer therapy dropouts, and higher possible dosages (e.g. anthracycline-based chemotherapy in aggressive non-Hodgkin's lymphoma [37]).

Concentrations of selenium in serum and whole blood provide useful indicators of selenium status of cancer patients. A serum selenium concentration of 100-120 $\mu \mathrm{g} / \mathrm{l}$ (corresponding $120-140 \mu \mathrm{g} / \mathrm{l}$ in whole blood) is suggested as being necessary for normal activity of selenoproteins (e.g. glutathione peroxidase, selenoprotein $\mathrm{P}$ ) and reflects an adequate selenium intake $[38,39]$. Before cancer patients take supplements with selenium (e.g. sodium selenite), the individual selenium status should be measured (e.g. selenium in whole blood). Selenium supplements are available in several forms: the organic form selenomethionine and the inorganic form sodium selenite. In complementary cancer therapy, the inorganic form sodium selenite is generally preferable to selenomethionine, because a part of the ingested selenomethionine is non-specifically incorporated into body proteins and can therefore accumulate in the body. In contrast, the selenium derived from sodium selenite is directly available for selenoprotein biosynthesis and can be better therapeutically controlled [40].

\section{Vitamin C (Ascorbic Acid)}

The antioxidant perhaps most widely used in complementary oncology is vitamin $\mathrm{C}$, particularly by intravenous injection. The possibility that vitamin $\mathrm{C}$ may be useful in the treatment of cancer was first raised by Cameron and Campbell in 1974. Subsequently, Pauling et al. [41] published research suggesting a survival benefit and improvement of quality of life in terminal cancer patients from high doses of vitamin C (10 g/day intravenously for 10 days followed by at least $10 \mathrm{~g} /$ day orally indefinitely). However, 2 randomized placebo-controlled studies conducted at the Mayo Clinic found no difference in outcome between terminal cancer patients receiving $10 \mathrm{~g}$ vitamin C per day orally or placebo [42]. It should be mentioned that there were significant methodological differences between the Mayo Clinic and Pauling studies. Although similar doses of vitamin $\mathrm{C}$ were used, the Pauling studies combined intravenous and oral administration, whereas the Mayo Clinic studies used only oral administration. Recent pharmacokinetics modeling [43] indicates that with oral administration, even very large doses of vitamin $\mathrm{C}$ will increase plasma concentrations only modestly to a maximum of approximately $230 \mu \mathrm{mol} / 1$, whereas intravenous administration can raise plasma concentrations 
as high as $14,000 \mu \mathrm{mol} / \mathrm{l}$. Concentrations of $1,000 \mu \mathrm{mol} / \mathrm{l}$ and more are selectively cytotoxic to tumor cells in vitro, and emerging evidence indicates that ascorbic acid at concentrations achieved by the intravenous route may function as a prodrug for hydrogen peroxide delivery to tissues (fig. 2) [44-48]. In a recent study by Chen et al. [49], parenteral application of ascorbate in pharmacologic doses ( $2-4 \mathrm{~g} / \mathrm{kg}$ body weight) significantly decreased growth rates of ovarian $(\mathrm{p}<0.005)$, pancreatic $(\mathrm{p}<0.05)$, and glioblastoma $(\mathrm{p}<0.001)$ tumors established in mice. Similar pharmacologic concentrations were readily achieved in humans given ascorbate intravenously. The data suggest that ascorbate as a prodrug may have benefits in cancers with poor prognosis and limited therapeutic options.

A non-interventional study at the University of Kansas describes favorable effects of tumor treatment and a concomitant reduction of side effects in 2 women with advanced epithelial ovarian cancer (stage IIIc) given defined oral doses of antioxidants and a high-dose intravenous vitamin $\mathrm{C}$ therapy [50]. In this study, the ovarian cancer patients took regular high-dose dietary antioxidant supplements after a primary operation either during first-line chemotherapy or consolidation therapy with carboplatin and paclitaxel. In addition, they were given intravenous high-dose vitamin $\mathrm{C}$ injections once or twice weekly (dosage $60 \mathrm{~g}$ /infusion), over a period of 40 months. To prevent the possibility of hemolysis, glucose-6-phosphate dehydrogenase (G6PD) status was assessed prior to intravenous ascorbic acid. The vitamin $\mathrm{C}$ infusions were started at $15 \mathrm{~g} / \mathrm{in}$ fusion and increased to $60 \mathrm{~g} /$ infusion given twice weekly. The dosage was calculated to achieve an effective concentration of $>200 \mathrm{mg} / \mathrm{dl}$ vitamin $\mathrm{C}$ in plasma. At this plasma level, ascorbic acid is reported to promote neoplastic cell cytotoxicity $[47,51]$. Both patients showed a favorable effect regarding the frequency of adverse effects of chemotherapy (e.g. neurotoxicity or myelosuppression by paclitaxel) and the duration of remission (e.g. tumor marker CA 125) as well as quality of life [50]. Because of the positive results found in the 2 reported patients, a randomized controlled trial is now underway at the University of Kansas Medical Center to further evaluate safety and efficacy of antioxidants when added to chemotherapy in newly diagnosed ovarian cancer (Jeanne A. Drisko,
MD, University of Kansas Medical Center, Program in Integrative Medicine, 3901 Rainbow Blvd., Kansas City, Kansas 66160; jdrisko@kumc.edu).

In light of the recent clinical pharmacokinetic findings, the in vitro evidence of anti-tumor mechanisms, and some welldocumented cases of advanced cancers, the role of high-dose intravenous vitamin $\mathrm{C}$ therapy in cancer treatment should be reassessed. High-dose intravenous vitamin $\mathrm{C}$ therapy may have benefits in patients with advanced cancers and cancers with poor prognosis and limited therapeutic options, but further clinical studies as to the safety and efficacy of this therapy are warranted.

Before application of high-dose vitamin $\mathrm{C}$ infusions, glucose6-phosphate dehydrogenase (G6-PD) deficiency should be ruled out, as red blood cell hemolysis may occur in people found to be deficient in the G6-PD enzyme. There is also a concern for renal calculi in oxalate kidney stone formers. History of renal calculi should be established, and patients' serum creatinine and renal function should be monitored regularly during treatment.

\section{Rationale for Micronutrients in Complementary Oncology}

Micronutrients have considerable potential in the prevention and adjuvant treatment of diet-related diseases. In complementary oncology, the administration of vitamins and other micronutrients tailored to individual needs can help to reduce the frequency of side effects from antineoplastic treatment and improve its effectiveness and therapeutic index through better compliance, fewer therapy dropouts, and higher possible dosages, and improve quality of life for the tumor patient.

\section{Supplemental Table File}

Table 8. Randomized clinical trials with glutathione, vitamin E, various antioxidants, and antioxidant combinations and chemotherapy (selection) [32].

For further information plase refer to

www. karger.com/doi/10.1159/000194972.

\section{References}

1 Molassiotis A, Fernadez-Ortega P, et al.: Use of complementary and alternative medicine in cancer patients: a European survey. Ann Oncol 2005;16 655-663.

2 Omenn GS, Goodman GE, et al.: Effects of a combination of beta carotene and vitamin A on lung cancer and cardiovascular disease. N Engl J Med 1996;334:1150-1155.

3 Alpha-Tocopherol BCCPSG: The effect of vitamin $\mathrm{E}$ and beta carotene on the incidence of lung can cer and other cancers in male smokers. N Engl J Med 1994;330:1029-1035.
4 Bjelakovic G, Nikolova D, et al.: Antioxidant supplements for prevention of gastrointestinal cancers: a systematic review and meta-analysis. Lancet 2004;364:1219-1228.

5 Prasad KN: Antioxidants in cancer care: when and how to use them as an adjunct to standard and experimental therapies. Exp Rev Anticancer Ther 2003;3:903-915.

6 D'Andrea G: Use of antioxidants during chemotherapy and radiotherapy should be avoided. CA Cancer J Clin 2005;55:319-321.
7 Renshaw GL, Barrett RA, et al.: The incidence of the risk of malnutrition in adult medical oncology outpatients and commonly-associated symptoms. J Hum Nutr Diet 2008;21:399-400.

8 Pirlich M, Schütz T, et al.: The German hospital malnutrition study. Clin Nutr 2006;25:563-572.

9 Arends J: Mangelernährung bei Tumorpatienten: Ursachen, Diagnostik, Kodierung. Der Onkologe 2008;14:9-14.

10 Gröber U: Micronutrients. Stuttgart, Medpharm, Scientific publishers, 2009, p. 480. 
11 Dewys WD, Begg C, et al.: Prognostic effect of weight loss prior to chemotherapy in cancer patients. Am J Med 1980;69:491-497.

12 Zürcher G: Medikamentöse Strategien zur Gewichtszunahme bei kachektischen Patienten. Akt Ernährungsmed 2002;27:398-407.

13 Jordan A, Stein J: Pathophysiologie der Tumorkachexie. Ernährungsumschau 1997;44:250-254.

14 Mayland C, Allen KR, et al.: Micronutrient concentrations in patients with malignant disease: effect of the inflammatory response. Ann Clin Biochem 2004; 41:138-141.

15 Zürcher G: Mangelernährung bei onkologischen Patienten; in Biesalski HK, Köhrle J, Schümann K (Hrsg.): Vitamine, Spurenelemente und Mineralstoffe. Stuttgart, Thieme Verlag, 2002.

16 Burney PG, Comstock GW, et al.: Serologic precursors of cancer: serum micronutrients and the subsequent risk of pancreatic cancer. Am J Clin Nutr 1989;49:895-900.

17 Brooks JD, Metter EJ, et al.: Plasma selenium level before diagnosis and the risk of prostate cancer development. J Urol 2001;166:2034-2038.

-18 Vogt TM, Ziegler RG, et al.: Serum selenium and risk of prostate cancer in U.S. blacks and whites. Int J Cancer 2003;103:644-670.

19 Wright ME, Weinstein SJ, et al.: Supplemental and dietary vitamin $\mathrm{E}$ intakes and risk of prostate cancer in a large prospective study. Cancer Epidemiol Biomarkers Prev 2007;16:1128-1135.

20 Kuo SH, Debnam JM, et al.: Wernicke's encephalopathy: an underrecognized and reversible cause of confusional state in cancer patients. Oncology 2008;76:10-18.

21 Plant AS, Tisman G: Frequency of combined deficiencies of vitamin D and holotranscobalamin in cancer patients. Nutr Cancer 2006;56:143-148.

22 Mayland CR, Bennett MI, et al.: Vitamin C deficiency in cancer patients. Palliat Med 2005;19:1720.

23 Büntzel J, Glatzel M, et al.: Status of essential trace elements in untreated carcinomas of the head and neck. Laryngorhinootologie 2003;82:573-577.

24 Goodman and Gilman's The Pharmacological Basis of Therapeutics, 10th ed. New York, McGraw-Hill, Medical Publishing Division, 2001.

25 Gröber U: Arzneimittel und Mikronährstoffe. Medikationsorientierte Supplementierung. Stuttgart Wissenschaftliche Verlagsgesellschaft, 2007.

26 Moss RW: Should patients undergoing chemotherapy and radiotherapy be prescribed antioxidants? Integr Cancer Ther 2006;5:63-82.

27 Prasad, KN, Kumar A, et al.: High doses of multiple antioxidant vitamins: essential ingredients in improving the efficacy of standard cancer therapy. J Am Coll Nutr 1999;18:13-25.

28 Kumar B, Jha MN, et al.: D-alpha tocopheryl succinate (vitamin E) enhances radiation-induced chromosomal damage levels in human cancer cells but reduces it in normal cells. J Am Coll Nutr 2002; 21:339-343

29 Block KI, Koch AC, et al.: Impact of antioxidant supplementation on chemotherapeutic efficacy: a systematic review of the evidence from randomized controlled trials. Cancer Treat Rev 2007;33:407418.

30 Pace A, Savarese A, et al.: Neuroprotective effect of vitamin $\mathrm{E}$ supplementation in patients treated with cisplatin chemotherapy. J Clin Oncol 2003;21: 927-931.
1 Jaakkola K, Lahteenmaki P, et al.: Treatment with antioxidant and other nutrients in combination with chemotherapy and irradiation in patients with small-cell lung cancer. Anticancer Res 1992;12:599_ 606.

32 Block KI, Koch AC, et al.: Impact of antioxidant supplementation on chemotherapeutic toxicity: a systematic review of the evidence from randomized controlled trials. Int J Cancer 2008;123:1227-1239.

33 Bleys J, Navas-Acien A, et al.: Serum selenium levels and all-cause, cancer, and cardiovascular mortality among US adults. Arch Intern Med 2008; 168:404-410.

34 Pawlowicz Z, Zachara BA, et al.: Blood selenium concentrations and glutathione peroxidase activities in patients with breast cancer and with advanced gastrointestinal cancer. J Trace Elem Electrolytes Health Dis 1991;5:275-277.

$35 \mathrm{Hu}$ YJ, Chen Y, et al.: The protective role of selenium on the toxicity of cisplatin-contained chemotherapy regimen in cancer patients. Biol Trace Elem Res 1997;56:331-341.

36 Von Büntzel J, Kisters K, Micke O, Mücke R (Hrsg.): Zytoprotektion, Spurenelemente und Elektrolyte in der Tumortherapie. München, Dustri-Verlag Dr. Karl Feistle, 2004.

37 Last KW, Cornelius V, et al.: Presentation serum selenium predicts for overall survival, dose delivery, and first treatment response in aggressive nonHodgkin's lymphoma. J Clin Oncol 2004;22:3429.

38 Lyons GH, Judson GJ, et al.: Trends in selenium status of South Australians. MJA 2004;180:383-386.

39 Expertenworkshop: Selen in Prävention und Therapie. Ärzte Zeitung 2008;27:1-5.

40 Köhrle J: Selen; in Biesalski HK, Köhrle J, Schümann K (Hrsg.): Vitamine, Spurenelemente und Mineralstoffe. Stuttgart, Thieme Verlag, 2002.

41 Cameron E, Pauling L: Supplemental ascorbate in the supportive treatment of cancer: Prolongation of survival times in terminal human cancer. Proc Natl Acad Sci U S A 1976;73:3685-3689.

42 Moertel CG, Fleming TR, et al.: High-dose vitamin $\mathrm{C}$ versus placebo in the treatment of patients with advanced cancer who have had no prior chemotherapy. A randomized double-blind comparison. N Engl J Med 1985;312:137-141.

43 Padayatty SJ, Sun H, et al.: Vitamin C pharmacokinetics: implications for oral and intravenous use. Ann Intern Med 2004;140:533-537.

44 Bram S, Froussard P, et al.: Vitamin C preferential toxicity for malignant melanoma cells. Nature 1980;284:629-631.

45 Leung PY, Miyashita K, et al.: Cytotoxic effect of ascorbate and its derivatives on cultured malignant and nonmalignant cell lines. Anticancer Res 1993;13:475-480.

46 Casciari JJ, Riordan NH, et al.: Cytotoxicity of ascorbate, lipoic acid, and other antioxidants in hollow fibre in vitro tumours. Br J Cancer 2001;84:15441550.

47 Chen Q, Espey MG, Krishna MC, et al.: Pharmacologic ascorbic acid concentrations selectively kill cancer cells: action as a pro-drug to deliver hydrogen peroxide to tissues. Proc Natl Acad Sci U S A 2005; 102:13604-13609.

48 Gröber U: Mikronährstoffe: Vitamin C - aktuell und kompakt. DAZ 2008;148:104-107.

49 Chen Q, Espey MG, et al.: Pharmacologic doses of ascorbate act as a prooxidant and decrease growth of aggressive tumor xenografts in mice. Proc Natl Acad Sci U S A 2008;105:11037-11038.
50 Drisko JA, Chapman J, et al.: The use of antioxidants with first-line chemotherapy in two cases of ovarian cancer. J Am Coll Nutr 2003;22:118-123.

51 Padayatty SJ, Riordan HD, et al.: Intravenously administered vitamin $\mathrm{C}$ as cancer therapy: three cases. CMAJ 2006;174:937-942.

52 Lajer H, Kristensen M, et al.: Magnesium and potassium homeostasis during cisplatin treatment. Cancer Chemother Pharmacol 2005;55:231-236.

53 Heuberger W, Berardi S, et al.: Increased urinary excretion of carnitine in patients treated with cisplatin. Eur J Clin Pharmacol 1998;54:503-508.

54 Niyikiza C, Baker SD, et al.: Homocysteine and methylmalonic acid: markers to predict and avoid toxicity from pemetrexed therapy. Mol Cancer Ther 2002;1:545-552.

55 Ohe Y, Ichinose Y, et al.: Efficacy and safety of two doses of pemetrexed supplemented with folic acid and vitamin B12 in previously treated patients with non-small cell lung cancer. Clin Cancer Res 2008;14:4206-4212.

56 Kondo, K, Fujiwara M, et al.: Severe acute metabolic acidosis and Wernicke's encephalopathy following chemotherapy with 5-fluorouracil and cisplatin: case report and review of the literature. Jpn J Clin Oncol 1996;26:234-236.

57 Marthaler NP, Visarius T, et al.: Increased urinary losses of carnitine during ifosfamide chemotherapy. Cancer Chemother Pharmacol 1999;44:170-172.

58 Cascinu S, Catalano V, et al.: Neuroprotective effect of reduced glutathione on oxaliplatin-based chemotherapy in advanced colorectal cancer: a randomized, double-blind, placebo-controlled trial. J Clin Oncol 2002;20:3478-3483.

59 Bogliun G, Marzorati L, et al.: Neurotoxicity of cisplatin $+/$ - reduced glutathione in firstline treatment of advanced ovarian cancer. Int J Gynecol Cancer 1996:6:415-419.

60 Fujimoto S, Miyazaki M, et al.: Clinical evaluation of prolonged chemotherapy combined with induction of hepatic drug-metabolizing enzymes as an adjuvant for treating patients with gastric cancer. Jpn J Surg 1983;13:486-492.

61 Argyriou AA, Chroni E, et al.: A randomized controlled trial evaluating the efficacy and safety of vitamin $\mathrm{E}$ supplementation for protection against cisplatin-induced peripheral neuropathy: final results. Support Care Cancer 2006;14:1134-1140.

62 Weijl NI, Elsendoorn TJ, et al.: Supplementation with antioxidant micronutrients and chemotherapy-induced toxicity in cancer patients treated with cisplatin-based chemotherapy: a randomized, double-blind, placebo-controlled study. Eur J Cancer 2004;40:1713-1723.

63 Iarussi D, Auricchio U, et al.: Protective effect of coenzyme Q10 on anthracyclines cardiotoxicity: control study in children with acute lymphoblastic leukemia and non-Hodgkin lymphoma. Mol Aspects Med 1994;15S:S207-S12.

64 Sieja K, Talerczyk M: Selenium as an element in the treatment of ovarian cancer in women receiving chemotherapy. Gynecol Oncol 2004;93:320-327.

65 Federico A, Iodice P, et al.: Effects of selenium and zinc supplementation on nutritional status in patients with cancer of digestive tract. Eur J Clin Nutr 2001;55:293-297.

66 Argyriou, Chroni E, et al.: Preventing paclitaxelinduced peripheral neuropathy: a phase II trial of vitamin E supplementation. J Pain Symptom Manage 2006;32:327-244. 